\title{
Trends in postpartum maternal morbidity in Ikot Ekpene a rural community in Southern Nigeria
}

\author{
Etim Inyang Ekanem ${ }^{1 *}$, Efiok Eyo Efiok ${ }^{1}$, Atim Edet Udoh ${ }^{1}$, Etop Charles Anaikot ${ }^{2}$ \\ ${ }^{1}$ Department of Obstetrics and Gynaecology, University of Calabar Teaching Hospital, Calabar, Nigeria \\ ${ }^{2}$ Department of Obstetrics and Gynaecology, General Hospital Ikot Ekpene, Ikot Ekpene, Nigeria \\ Email: "ekanmetim@yahoo.com
}

Received 22 May 2013; revised 24 June 2013; accepted 3 July 2013

Copyright (c) 2013 Etim Inyang Ekanem et al. This is an open access article distributed under the Creative Commons Attribution License, which permits unrestricted use, distribution, and reproduction in any medium, provided the original work is properly cited.

\section{ABSTRACT}

Background: Postpartum maternal morbidity is becoming a major public health concern worldwide due to impact of modern development in feto-maternal medicine and maternal care. Major acute and long term maternal morbidities which may occur during obstetric management affect the life and reproductive career of women. Objective: To assess the trends, risk factors and pattern of postpartum maternal morbidity in Ikot Ekpene a local community in Southern Nigeria. Materials and Methods: This was a 4-year prospective cross sectional observational study carried out in the maternity section of General Hospital Ikot Ekpene, Akwa Ibom State, Nigeria between 2008 and 2011. Parturients managed in the hospital for postpartum morbidity were recruited for the study. Relevant information was obtained from structured questionnaire administered to the patients and those extracted from other medical records in the course of managing the patients. This was analysed using the SPSS computer statistical package. Result: A total of 5760 women delivered during the period, of which 296 (5.1\%) were treated for postpartum morbidity. Most of the patients (46.9\%) were between 31 and 40 years old and $68.8 \%$ were of low educational background. Half of the deliveries with morbidity were conducted by unskilled attendants. The most common maternal morbidity encountered included primary postpartum haemorrhage $(22.2 \%)$, genital sepsis (16.1\%), and hypertensive disorders (12.8\%). Anaemia $(12.8 \%)$ and malaria $(11.1 \%)$ were the commonest non obstetrics causes of morbidity. It was relatively more common with delivery attended by untrained personnel. There was significant reduction in morbidity in the last 2 years of this study. Conclusion: The incidence of postpartum morbidity in the Ikot

\footnotetext{
*Corresponding author.
}

Ekpene is still high with a downward trend over the years. Obstetric haemorrhage, hypertensive disorders, anaemia and genital tract sepsis were the common causes and were commoner with delivery attended by unskilled personnel. It is hoped that supervision of deliveries by skilled medical attendants, improvement in general health and educational level will reduce postpartum morbidity in this rural community.

Keywords: Haemorrhage; Hypertensive Disorders; Maternal; Morbidity; Postpartum; Trends

\section{INTRODUCTION}

The post partum period is very important but most neglected during obstetric care [1]. Most complications including death occur during this period [2]. The attention of most mothers, family members and birth attendants in rural community in developing countries is often diverted to cerebration and relief at the arrival of an expected new baby after much awaited periods of 9 months of pregnancy and stormy period of labour. The mother condition is considered when complications are noticed. This may result in avoidable morbidity [3].

Even though The World Health Organisation defines the postpartum period or purperium as beginning after the delivery of the placenta and continuing until 6 weeks (42 days) after the birth of infant, maternal morbidity generally refers to complications that arise during pregnancy, delivery or the postpartum period [1,4-6]. However, many of the postpartum complications that lead to maternal morbidity and mortality arise during labour, delivery and in the first 1 - 2 weeks following delivery [6-8].

The incidence of postpartum maternal morbidity is difficult to estimate due to lack of standard definitions and measuring criteria as well as poor data management system $[1,6,9,10]$. Generally, the burden of this problem is high in most resource constraints countries. In devel- 
oping countries, pregnancy and complications from childbirth account for $18 \%$ of the disease among females $[2,11]$. Out of the 585,000 women who die each year during childbirth, over 98\% are from the developing world. Again, for each woman that dies, 10 - 15 others suffer different forms of serious morbidity [5,6]. About $40 \%$ of the pregnant women in Nigeria experience pregnancy-related health problems during or after pregnancy and childbirth with an estimated 15\% suffering from serious or long term complications [4,6,12]. Major acute obstetric morbidities like haemorrhage, sepsis, genital tract injuries, wound infections and long term morbidities such as uterine prolapsed, urinary incontinence, dysparunia and infertility are well documented [1,4,13-16]. In recent times the rising incidences of none pregnancy related morbidity such as anaemia, malaria, hypertension and chronic chest infections have been reported in developing countries with major impact on maternal health and wellbeing $[6,17,18]$. While in developed countries of the world, the incidences of these common morbidities are reducing, severe acute maternal morbidly (SAMM) or "near miss" condition is becoming prevalent $[10,17,19$, 20]. The latter is related to effective obstetric care resulting in reduction in mortality and many patients now end up with severe morbidity.

Good antenatal care and skilled attendants at delivery have long been identified as major factors at reducing maternal injuries, morbidity and mortality [4,6,21]. Many national and international programs/agencies have been put in place to emphasize their importance with variable results. Currently, many policies and programs are being put in place by governments in most developing countries with emphasise on postpartum care to expand the scope of previous practices to create more impact at reducing the maternal mortality and morbidity $[8,20,21]$. In line with this consideration, the government of Akwa Ibom State in the Niger Delta Region of Nigeria has upgraded General Hospital Ikot Ekpene, a secondary heath care facility to offer specialist care to the people of the rural community. It is therefore, necessary to assess the impacts of these programs on postpartum maternal morbidity over the period in the hospital.

The study was therefore, carried out in the hospital with the aims of assessing the trend, incidence, type of maternal morbidity and socio-demographic variable of the patients. It is hoped that the results of this study will help to create baseline data to assess maternal morbidity in future studies and identify the main factor(s) that contribute to these injuries with subsequent strategies for prevention and early treatments to avoid long term complications.

\section{MATERIAL AND METHODS}

This study was conducted in the maternity section of the
General Hospital Ikot Ekpene, Akwa Ibom State of Nigeria over a 4 years period $\left(1^{\text {st }}\right.$ January 2008 and $31^{\text {st }}$ December 2011).

The hospital is a secondary health facility in the senatorial district of the state upgraded to offer specialist care to the over a million people. It therefore, receives patients that present themselves directly for care or referred from other secondary facilities, private clinics and health centres across the state and beyond.

The hospital has an annual delivery rate of 1700 women and caesarean delivery rate of $30.1 \%$.

The people of rural community are mainly farmers, house wives, petty traders and public servants. There is high fertility rate of 7.1, crude birth rate 40 per 1000 and low female literacy level.

\subsection{Ethical Approval}

Written approval was obtained from the ethical committee of the institution and unwritten informed consent from the women after careful and personal discussions with each of them by the authors. Patients who refused to give consent for the study were reassured of receiving standard care without bias irrespective of her decision.

\subsection{Setting}

The maternity section of General Hospital Ikot Ekpene Akwa Ibom State.

\subsection{Patients' Recruitment}

Cases managed for post partum morbidities in the hospital from delivery of the baby to 42 days after delivery were recruited irrespective of booking status, mode of delivery, the attendants at delivery or types of morbidity. Also included were those that delivered outside the hospital but present or referred to the hospital for treatments.

\subsection{Exclusion}

Those excluded from the study were delivery occurring before 28 weeks of gestation, patients that arrived the hospital but died before admission to the ward; those with pre-existing non obstetric morbidity before the pregnancy; those that diagnosis were not certain; Those who developed complications but later died and those who refused to give consent for the study. The latest group were assured and given standard treatment irrespective of their decision

\subsection{Methods}

Comprehensive medical history and physical examination were conducted on all the patients included in the study on admission in the hospital. Appropriate laboratory investigations and standard management based on 
the hospital policy were instituted on each the patients. Relevant information was then obtained from the patients using pretested semi structured questionnaire on admission to the ward or as soon as the clinical condition is stable; on discharge from ward and in the 6th week postnatal clinic. Information for each patient was also extracted from case records in the operation theatre, wards, laboratory and health information unit of the hospital. Information obtained included date of delivery, sociodemographic and reproductive characteristics of the patient, booking status, mode of delivery, accoucher, post delivery complications and duration of hospital stay.

\subsection{Data Analysis}

The data entry and analysis were done using SPSS version 12 computer statistical package. To minimize inconsistent and wrong entries, the check option was used to program the data entry exercise for the descriptive aspect of the analysis and frequency distribution were generated for all the categorical variables.

All the patients were then managed according to the hospital protocol for the diagnosis.

For the purpose of this study the following definitions are applicable:

1) Post partum morbidity was defined as any complications occurring in the parturients from the delivery of the baby upto 6 weeks after delivery

2) Unbooked patients referred to those who did register and have antenatal care in any recognised health institutions. It also includes those who had antenatal care but attempted delivery with unskilled personnel.

3) Skilled attendants referred to those with appropriate training in government recognised institutions to supervised delivery.

4) For patients with more than one morbidity the most serious complication was recorded.

5) Severe acute maternal morbidity (SAMM) was diagnosed when one or more organ damage was diagnosed.

6) Anaemia was defined as haemoglobin concentration of less than 10 grams decilitre (g/dl).

\section{RESULTS}

A total of 5750 deliveries were conducted in the hospital during the 4 years period and 296 patients were managed for postpartum morbidity giving incidence of $5.1 \%$. However records of 288 patients were satisfactory for analysis.

Table 1 shows the socio-demographic and reproductive characteristics of patients with morbidity. Even though most of the patients (46.9\%) were 31 - 40 years old $17.7 \%$ were teenagers. Majority had some level of formal education with 21 (7.3\%) having higher education. They were mainly farmers (33.7\%) and multiparous but
72 (25\%) were primiparous. Most morbidity (66.0\%) occurred in women with term delivery but $19.4 \%$ and $14.6 \%$ were diagnosed after preterm and postdate deliveries respectively.

As shown in Table 2, 207 (71.8\%) of the complications occurred after vaginal deliveries and 52 (18.1\%) followed caesarean deliveries. Majority followed delivery by unskilled attendants (35.1\%) while 32 (11.2\%) complicated deliveries conducted by the medical officers. Also, 163 (56.6\%) booked patients had complications.

Table 3 shows that the most common morbidity was primary postpartum haemorrhage (22.2\%). This was followed by genital sepsis in $46(16.1 \%)$ of the patients. Hypertensive disorders complicated 34 (11.8\%) deliveries and retained placenta occurred in 14 (4.9\%). Anaemia and malaria were the commonest non obstetric related

Table 1. Socio-demographic and reproductive characteristics of the patients with postpartum morbidity.

\begin{tabular}{|c|c|c|}
\hline & N 288 & $\%$ \\
\hline Age (years) & & 100 \\
\hline $13-19$ & 51 & 17.7 \\
\hline $20-30$ & 77 & 26.7 \\
\hline $31-40$ & 135 & 46.9 \\
\hline $41-50$ & 25 & 8.7 \\
\hline \multicolumn{3}{|l|}{ Educational level } \\
\hline None & 80 & 27.8 \\
\hline Primary & 118 & 41.0 \\
\hline Secondary & 69 & 23.9 \\
\hline Post secondary & 21 & 7.3 \\
\hline \multicolumn{3}{|l|}{ Occupations } \\
\hline Housewives & 82 & 28.5 \\
\hline Farming & 97 & 33.7 \\
\hline Trading & 54 & 18.7 \\
\hline Civil Servant & 32 & 11.1 \\
\hline Others & 23 & 8.0 \\
\hline \multicolumn{3}{|l|}{ Parity } \\
\hline 1 & 72 & 25 \\
\hline $2-4$ & 175 & 61 \\
\hline $5-12$ & 41 & 14 \\
\hline \multicolumn{3}{|c|}{ Gestational age at delivery } \\
\hline $28-36$ & 56 & 19.4 \\
\hline $37-40$ & 190 & 66.0 \\
\hline $41-42$ & 42 & 14.6 \\
\hline
\end{tabular}


Table 2. Distribution of patients with morbidity by mode of delivery, attendants and booking status.

\begin{tabular}{ccc}
\hline & $\mathrm{N}=288$ & $\%$ \\
\hline Mode of delivery & 207 & 71.8 \\
Vaginal delivery & 52 & 18.1 \\
Caesarean section & 29 & 10.1 \\
Others & & \\
Attendants at delivery & 101 & 35.1 \\
Traditional birth attendants & 43 & 14.9 \\
Community health and exten- & sion officers \\
Midwives & 61 & 21.1 \\
Medical officers & 32 & 11.2 \\
Others & 51 & 17.7 \\
Booking status & & \\
Booked & 163 & 56.6 \\
Unbooked & 125 & 43.4 \\
\hline
\end{tabular}

Table 3. Distribution of patients by postpartum morbidity and duration between delivery and diagnosis of complications.

\begin{tabular}{ccc}
\hline & No & $\%$ \\
\hline Post-partum morbidity & & \\
Postpartum haemorrhage & 64 & 22.2 \\
Genital sepsis & 46 & 16.1 \\
Anaemia & 37 & 12.8 \\
Hypertensive disorders/eclampsia & 34 & 11.8 \\
Puerperal pyrexia/Malaria & 32 & 11.1 \\
Genital laceration/episiotomy & 26 & 9.0 \\
Wound dehiscence/infections & 24 & 8.3 \\
Retained placenta & 14 & 4.9 \\
Others & 11 & 3.8 \\
Duration between delivery and & & \\
diagnosis (days) & 13 & 4.5 \\
$<1$ & 229 & 65.9 \\
1 - 7 & 36 & 12.5 \\
$8-14$ & 7 & 2.4 \\
15 - 21 & 3 & 1.1 \\
$>21$ & &
\end{tabular}

morbidities in 37 (12.8\%) and 32 (11.1\%) respectively. Severe acute maternal morbidity was diagnosed in 4 patients.

Most of the complications were diagnosed after 24 hours of delivery with only 13 (4.5\%) seen within the first day and 3 (1.1\%) after 21 days.

Table 4 shows the trend in maternal morbidity and the category of attendants at delivery during the period.

Out of the 288 morbidity encountered 101 (35.1\%) were delivered by the untrained traditional birth attendants followed by trained midwives in 61 (21.1\%) while medical officers delivered only $11.2 \%$ of them. The highest number of morbidity (6.4\%) was obtained in 2008 while least of 61 (3.8\%) was obtained in 2011 despite recording the highest number of delivery. Overall deliveries conducted by the medical officers carry the least risk morbidity over the period.

\section{DISCUSSION}

The incidence of $5.1 \%$ of postpartum maternal morbidity in this hospital appears high when compared with the study in some part of Nigeria and other developing countries of $2 \%-3 \%$ [2] and much higher than those from developed countries of the world of less than $1 \%$ $[11,20]$. It is however in accord with reports from other parts of Nigeria (Jos, 4\% Cross River State 4.6\%), Zambia (4.2\%), Niger republic (6.45\%), Senegal (7.5\%) and Pakistan $(4 \%)[4,8,15]$. This variation in incidence may be related to lack of standard definition, operation guidelines and diagnostic criteria. It is also a reflection of the differences in quality and utilization of reproductive health services in the developed and developing countries of the world [21-23]. The incidence in our study may not be a true reflection of the burden of this problem in the society as only a third of delivery takes place in the hospital and some of our women with these complications may not have access to hospital for reasons ranging from ignorance, poverty, lack of transportation and influence of traditional/religious believes. Sometimes, in our traditional society it is believed that injuries at childbirth are best treated at home or in churches/ mosques with herbal remedies and other practices and only life threatening conditions sent to the hospital [22]. This study generally demonstrates that efforts by all stakeholders in health care to reduce complications at childbirth have little impact in the rural community.

As reported by others in Nigeria and other developing countries $[1,2,13]$ most of the women with morbidity in our study were in the active reproductive age group (20 30 years), who are from low socio economic status and were poorly educated. This is unlike a study in Dhaka, Bangladesh, where the frequency of the reported postpartum illness was significantly associated with both increasing maternal age and parity [4,23-25]. Also, a quarter of the patients in this study were well educated with $11.1 \%$ having well paid jobs. This later group may be influenced by various factors (including adverse traditional 
Table 4. Yearly trends of maternal morbidity and attendants at delivery.

\begin{tabular}{cccccc}
\hline \multirow{2}{*}{ Attendant at delivery } & Total & 2008 & 2009 & 2010 & 2011 \\
\cline { 2 - 5 } & $\mathrm{N}(\%)$ & $\mathrm{N}(\%)$ & $\mathrm{N}(\%)$ & $\mathrm{N}(\%)$ & $\mathrm{N}(\%)$ \\
\hline $\begin{array}{c}\text { Traditional birth } \\
\text { attendant }\end{array}$ & $101(35.1)$ & $30(33.7)$ & $21(29.1)$ & $29(44.0)$ & $21(34.4)$ \\
CHEW & $43(14.9)$ & $13(14.6)$ & $11(15.3)$ & $9(13.6)$ & $10(16.4)$ \\
Midwives & $61(21.1)$ & $16(18.0)$ & $18(25.0)$ & $10(15.2)$ & $17(27.8)$ \\
Medical officer & $32(11.2)$ & $12(13.5)$ & $9(12.5)$ & $6(4.5)$ & $8(13.1)$ \\
Morbidity & $288(5.6)$ & $89(6.4)$ & $72(4.8)$ & $14.2)$ & $61(3.8)$ \\
Total delivery & 5760 & $1382(23.9)$ & $1498(26.0)$ & $1613(28.2)$ \\
\hline
\end{tabular}

and religious believes) to have delivery outside the hospital with strong resistance to operative delivery $[8,23$, 24]. These eventually result in various forms morbidity like sepsis, urinary tract and genital injuries $[15,26]$.

In this study as in other reports most of the patients were multiparous (Para 2 - 4) with term pregnancy $[1,4,8$, 16]. These findings may be a reflection of our general obstetrics population. Unlike other reports however, we had many cases of primiparous and post date delivery with various forms of complications [1,12]. Though the main reason for this finding is unclear but may be related to increase operative interventions in this group patient to reduce complications. Also, some of the young primiparous women may be influenced by the older women in the society to attempt delivery with traditional birth attendants or other unskilled attendants as mark of protections against harm by the "evil spirit" which often believed to strike during labour [22-24]. The involvement of traditional and spiritual leaders in reproductive health programs and education would make them have positive influence on their subjects for proper utilization of such projects including hospital delivery.

Even though it has been shown that the absence of good antenatal care and hospital delivery usually leads to a high incidence of maternal morbidity and mortality $[4,6$, 16] more than half of the patients in this study were booked who had regular antenatal care in the hospital. This may imply that most the complications recorded developed in the course of labour and delivery. As noted in this study and others most deliveries were attended by unskilled attendants $[1,15,22]$. During the antenatal period the importance of hospital delivery in clean environment and skilled attendants should be emphasised. Training of birth attendants should include early recognition of the complications and appropriate referral. The need to make the hospital environment culturally/economically conducive and friendly to women would reduce the over $60 \%$ of the women that delivered in outside the hospital.

The leading postpartum maternal morbidity in this study was primary postpartum haemorrhage. This was followed by hypertensive disorders of pregnancy and puerperal sepsis. This is similar to other findings in South Africa and Niger Republic [3,11,15,17]. Obstetric haemorrhage accounted for more than half of the morbidity in Scotland and other developed countries [19,20]. Generally while the overall incidence of common morbidity is reducing in most developed countries of the world severe acute maternal morbidity ("Near Miss" cases) are common and post major challenges in management because of multiple major organ injuries $[1,7$, $11,15]$. It is gradually becoming apparent in some developing countries that with improved and sophisticated obstetric care cases that would have ended up in mortality are now living requiring critical care to prevent major organ damage. This is an emerging concept of obstetric practice which must be considered by planners of health facilities and policies in the resourced constrained like Nigeria.

In this study there was high proportion of non obstetric morbidity such as anaemia, post partum pyrexia and malaria. This is also the finding in other countries where tuberculosis and chest infections post major problem in the post partum period in Zambia [4,6,16]. These findings in our study may be due poor antimalarial prophylaxis policy in pregnancy and increase incidence of HIV/AIDS among the obstetric population. Also, as morbidity from other causes is being tackled this group of patients would be more apparent. As these conditions are known to have worse prognosis in pregnancy [27] there is compelling need to put in place effective programs for prevention, early detection and prompt treatment of these infections to reduce the morbidities associated with them.

Other morbidities encountered in this study included wound dehiscence following caesarean deliveries (8.5\%). This was less than the findings in Maiduguri [13] and higher than the figures obtained some tertiary institutions in Nigeria. The hygienic status of patients and that of the hospital environment, utilization of perioperative antibi- 
otics and surgical techniques of the surgeons could have accounted for these variations. In our practice most the patients were unbooked referred after many days in labour with advanced level of complications including sepsis before operative interventions.

The incidence of perineal injuries including episiotomy in this study appears higher than what is obtained by others in developing countries [4,6]. As reported by others these was prevalent among the primiparous women in this study. $[4,6,28]$ It appears routine episiotomy among this group of parturients are still being carried out by most attendants in our society. This should be discouraged as current scientific evidence shows that routine episiotomy is not justified [28]. There is no obvious benefit to the mother or infant. It increases the need for perineal suturing and the risk of complications to the healing process at 7 days postpartum. It also produces unnecessary pain and discomfort, and has potentially harmful long-term effect.

The incidence of retained placenta in this study appears lower than what is obtained from other studies in other part of Nigeria and much higher than those from developed countries [4,24]. A study in Ibadan, South Western Nigeria, found that the incidence of retained placenta in scared uterus was $5.3 \%$ while that in unscarred uterus was $1.74 \%$ but a study from Jos, Pakistan and Cross River were $0.8 \%, 20.8 \%$ and $25.0 \%$ respecttively $[1,4,6,15]$. This marked variation may be related to differences in diagnosis and protocol in the management of third stage of labour. Generally, this condition is associated with increase maternal morbidity and mortality. Even though the incidence of retained placenta is relatively low in this study, many cases of morbidly adherent placenta in unscarred uteri were encountered with subsequent operative interventions. This is very instructive as these cases were encountered in deliveries that were supervised by unskilled attendants and midwives who might not have anticipated the possibility of these complications. Also, many of our patients had retained placenta for days at home and appeared in the hospital in very bad state but survived with appropriate intervenetions.

Our study (Table 4) showed a gradual reduction of incidence of morbidity with increasing number of delivery over the period except 2010. In 2010 there was industrial dispute in the hospital and few cases (4.6\%) were delivered by the medical officers. The reduction in the prevalence of common postpartum morbidities has been reported by others $[3,12,15,17]$. These findings in our study is in keeping with the expectation that maternal mortality and morbidity will be drastically reduced if patients are managed in a well equipped health facilities that is manned by committed and well trained personnel coupled with effective referral system [22].
The main limitations of this study include the fact that it was hospital based with relatively small sample size. Patients who presented in the main general outpatient clinic or accident and emergency department were not included. Multicentre community based epidemiological to include larger area of the society is being proposed. This would help to answer some the question and fill the gap which this study has created.

\section{CONCLUSION}

The incidence of postpartum morbidity in this study is high, with haemorrhage, hypertensive disorders and sepsis being the common problems. There was a gradual reduction over the period but the non obstetric causes are becoming more prevalent. Since many of the complications that led to post partum maternal morbidity arise during labour and delivery, with an inverse relationship between postpartum morbidity and skilled accoucher, proper supervision should be given to parturient in order to minimize these complications. It is also necessary to reiterate the need for properly supervised labour and prompt use of oxytocics to prevent postpartum haemorrhage. It is necessary to maintain the trend of the reducetion noted in this study by improving the infrastructural facilities and attention paid to staff welfare.

\section{REFERENCES}

[1] Bibi, S., Ghaffar, S., Memon, S. and Memon, S. (2012) Severe acute maternal morbidity (SAMM) in postpartum period requiring tertiary hospital care. Iranian Journal of Reproductive Medicine, 10, 87-92.

[2] Utoo, B.T., Musa, J., Karshima, J.A. and Ifenne, D.I. (2012) Maternal morbidity after childbirth in a health care facility in south-South Nigeria. Tropical Journal of Obstetrics and Gynaecology, 29, 34-39

[3] Chabra, P., Guleria, K., Saini, N.K., Anjur, K.T. and Vaid, N.B. (2008) Pattern of severe maternal morbidity in a tertiary hospital of Delhi, India: A pilot study. Tropical Doctor, 38, 201-204. doi:10.1258/td.2007.070327

[4] Vallely, L., Ahmed, Y. and Murray, S.F. (2005) Postpartum maternal morbidity requiring hospital admission in Lusaka, Zambia-A descriptive study. BMC Pregnancy and Childbirth, 5, 1.

[5] World Health Organization (1998) Postpartum care of the mother and newborn: A practical guide. Geneva.

[6] Mutihir, J.T. and Utoo, B.T. (2011) Postpartum maternal morbidity in Jos, North Central Nigeria. Nigerian Journal of Clinical Practice, 1, 38-42

[7] Minkauskiene, M., Nadisaskiene, R., Padinga, Z. and Makari, S. (2004) Systematic review of the incidence and prevalence of severe maternal morbidity. Medicina, 40, 299-309.

[8] Lagro, M., Liche, A., Mumba, R., Ntebka, R. and Van Roosemalan, J. (2003) Postpartum health among rural 
Zambian women. African Journal of Reproductive Health, 7, 41-48. doi: $10.2307 / 3583287$

[9] Souza1, J.P., Cecatti, J.G., Parpinelli, M.A., Serruya, S.J. and Amaral, E. (2007) Appropriate criteria for identification of near-miss maternal morbidity in tertiary care facilities: A cross sectional study. BMC Pregnancy Childbirth, 7, 20. doi:10.1186/1471-2393-7-20

[10] Mantel, G.D., Buchmann, E., Rees, H. and Pattinson, R.C. (1998) Severe acute maternal morbidity: A pilot study of a definition for a near-miss. British Journal of Obstetrics and Gynaecology, 105, 985-900. doi:10.1111/j.1471-0528.1998.tb10262.x

[11] Ronsmans, C. (2009) Severe acute maternal morbidity in low income countries. Best Practice \& Research Clinical Obstetrics \& Gynaecology, 23, 305-316. doi:10.1016/j.bpobgyn.2009.01.001

[12] Patra, S., Singh, B. and Reddaiah, V.P. (2008) Maternal morbidity during postpartum period in a village of north India: A prospective study. Tropical Doctor, 38, 204-208. doi:10.1258/td.2008.070417

[13] Chama, C.M., El-Nafaty, A.U. and Idrisa, A. (2000) Caesarean morbidity and mortality at Maiduguri, Nigeria. Journal of Obstetrics Gynaecology, 20, 45-48. doi:10.1080/01443610063453

[14] Ronsmans, C., Achadi, E., Cohen, S. and Zazari, A. (1997) Women's recall of obstetric complications in South Kalimantan, Indonesia. Studies in Family Planning, 28, 203-214. doi:10.2307/2137888

[15] Prual, A., Huguet, D., Garbin, O. and Rabe, G. (1998) Severe obstetric morbidity of the third trimester, delivery and early puerperium in Niamey (Niger). African Journal of Reproductive Health, 2, 10-19.

[16] Lagro, M., Liche, A., Mumba, T., Ntebeka, R. and van Roosmalen, J. (2003) Postpartum health among rural Zambian women. African Journal of Reproductive Health, 7, 41-48. doi:10.2307/3583287

[17] Vanderuys, H.I., Paltinson, R.C., Macdonald, A.P. and mantel, G.D. (2002) Severe acute maternal morbidity and mortality in the Pretoria Academic Complex: Changing patterns over 4 years. European Journal of Obstetrics \& Gynecology and Reproductive Biology, 102, 6-10. doi:10.1016/S0301-2115(01)00558-9

[18] Prual, A., Huguest, D., Garbin, O. and Rabe, G. (1998) Severe obstetric morbidity of the third trimester, delivery and early puerperium in Niamey (Niger). African Journal of Reproductive Health, 2, 10-19.

[19] Baskett, T.F. and Connell, M.O. (2005) Severe obstetric maternal morbidity: A 15-year population-based study. Journal of Obstetrics Gynaecology, 25, 7-9. doi:10.1080/01674820400023408

[20] Brace, V., Penny, G. and Hall, M. (2004) Quantifying severe maternal morbidity: A Scottish population study. BJOG: An International Journal of Obstetrics \& Gynaecology, 111, 481-484. doi:10.1111/j.1471-0528.2004.00101.x

[21] Adamu, Y.M. and Salihu, H.M. (2002) Barriers to the use of antenatal and obstetric care services in rural Kano, Nigeria. Journal of Obstetrics \& Gynaecology, 22, 600-603. doi:10.1080/0144361021000020349

[22] Fikree, F.F., Ali, T., Durocher, J.M. and Rahbar, M.H. (2004) Health service utilization for perceived postpartum morbidity among poor women living in Karachi. Social Science \& Medicine, 59, 681-694. doi:10.1016/j.socscimed.2003.11.034

[23] Ebuchi, O.M. and Akintujoye, I.A. (2012) Perception and utilization of TBA by pregnant women attending primary health care clinic in a rural local government area in Ogun State, Nigeria. International Journal of Women's Health, 4, 25-34. doi:10.2147/IJWH.S23173

[24] Naz, H., Sarwar, I., Fawad, A. and Nisa, A.U. (2008) Maternal morbidity and mortality due to primary $\mathrm{PPH}$ -Experience at Ayub Teaching Hospital Abbottabad. Journal of Ayub Medical College Abbottabad, 20, 59-65.

[25] Goodburn, E.A., Gazi, R. and Chowdhury, M. (1995) Beliefs and practices regarding delivery and postpartum maternal morbidity in rural Bangladesh. Studies in Family Planning, 26, 22-32. doi:10.2307/2138048

[26] Dare, F.O., Bako, A.U. and Ezechi, O.C. (1998) Puerperal sepsis: A preventable postpartum complication. Tropical Doctor, 28, 92-95.

[27] Diagne, N., Rogier, C., Sokhna, C.S., Tall, A., Fontenille, D., Roussilhon, C., Spiegel, A. and Trape, J.F. (2000) Increased susceptibility to malaria during the early postpartum period. The New England Journal of Medicine, 343, 598-603. doi:10.1056/NEJM200008313430901

[28] Nager, C.W. and Helliwell, J.P. (2001) Episiotomy increases perineal laceration length in primiparous women. American Journal of Obstetrics \& Gynecology, 185, 444450. doi:10.1067/mob.2001.116095 